\title{
A new technique of internal suture mastopexy for mild to moderate breast ptosis
}

\author{
Raman Chaos Mahabir MD MSc FRCSC, William A Zamboni MD FACS
}

RC Mahabir, WA Zamboni. A new technique of internal suture mastopexy for mild to moderate breast ptosis. Can J Plast Surg 2008;16(1):11-13.

BACKGROUND: Current mastopexy techniques rely on incisions on the breast to correct ptosis. Trading a ptotic breast for a visibly scarred breast can be a difficult choice.

OBJECTIVE AND METHODS: A technique of internal suture mastopexy that consists of plicating sutures placed in the superficial fascia of the breast from the deep surface is presented. The procedure leaves no scar on the breast and may be safer than other techniques when combining mastopexy with augmentation.

RESULTS: The senior author has performed this procedure on over 120 patients, with a mean follow-up of two years. Patients and the surgeon have expressed satisfaction with the procedure.

CONCLUSION: Based on this experience with over 120 patients, the authors believe that internal suture mastopexy is an effective alternative in selected patients.

Key Words: Breast ptosis; Hypomastia; Mastopexy; Nipple-areola complex

ging, peripartum enlargement, postpartum involution and several other factors can contribute to the diminished elasticity breast tissues over time, the end result of which is a ptotic breast. True ptosis occurs when the nippleareola complex descends to a position that is level with or below the inframammary crease. In 1976, Regnault (1) described a classification of breast ptosis that remains in use today. The goal of mastopexy is to give the breast a natural, replete, youthful appearance. This is accomplished by tightening the skin brassiere (skin excision or implant insertion), elevating the nipple-areola complex or both. For minor degrees of breast ptosis, several sound options exist that produce excellent results. Rohrich et al (2) have recently published an excellent review of the current concept of limited scar mastopexy for mild to moderate ptosis. Currently, these techniques rely on breast incisions to correct ptosis. Trading a ptotic breast for a visibly scarred breast can be a difficult choice. In severe breast ptosis, a Wise breast reduction pattern (3) that results in an inverted-T scar will produce a reasonable and reliable result.

We present a technique for the correction of mild to moderate ptosis that does not leave a mastopexy scar on the breast. This technique is specifically applicable to patients requesting simultaneous augmentation and mastopexy or to patients who

\section{Nouvelle technique de mastopexie à sutures internes pour corriger les ptoses mammaires légères ou modérées}

CONTEXTE : Les techniques actuelles de mastopexie reposent sur les incisions pratiquées sur le sein pour corriger la ptose. Troquer la ptose mammaire pour une cicatrice visible peut poser problème.

BUT ET MÉTHODE : Il sera question, dans le présent article, d'une mastopexie à sutures internes, qui consiste en la plicature des sutures pratiquées dans le fascia superficiel du sein à partir de la couche profonde. L'intervention ne laisse aucune cicatrice et peut se révéler plus sûre que d'autres techniques dans les cas de mastopexie associée à une augmentation mammaire.

RÉSULTATS : L'intervention a été pratiquée par l'auteur principal sur plus de 120 patientes, et la durée moyenne du suivi était de deux ans. Les patientes et le chirurgien se sont dits satisfaits des résultats de l'intervention.

CONCLUSION : D'après l'expérience effectuée sur plus de 120 patientes, les auteurs sont d'avis que la mastopexie à sutures internes est une nouvelle technique de correction mammaire qui donne de bons résultats chez les femmes sélectionnées.

already have implants placed via an inframammary crease incision that now require mastopexy.

\section{PREOPERATIVE ANALYSIS}

The preoperative evaluation includes a careful examination of the breasts for asymmetry, both in nipple-areola position and in volume. It is important that the patient appreciate any asymmetries that exist preoperatively. Anterior-posterior, lateral, and right and left oblique views should be documented. As with any cosmetic procedure, it is imperative that the patient has realistic expectations and understands the limitations of the procedure. In higher degrees of ptosis (in which the nipple is to be repositioned more than $3 \mathrm{~cm}$ ), the option of conversion to a limited scar mastopexy should also be discussed.

\section{TECHNIQUE}

If an implant is to be placed, the operation begins with an inframammary crease incision. The subglandular pocket is developed and hemostasis ensured. A solution of ketorolac and bupivacaine with adrenaline is placed and left in the pocket to help with postoperative pain control (4). A lighted retractor is then used to visualize the anterior surface of the subglandular 


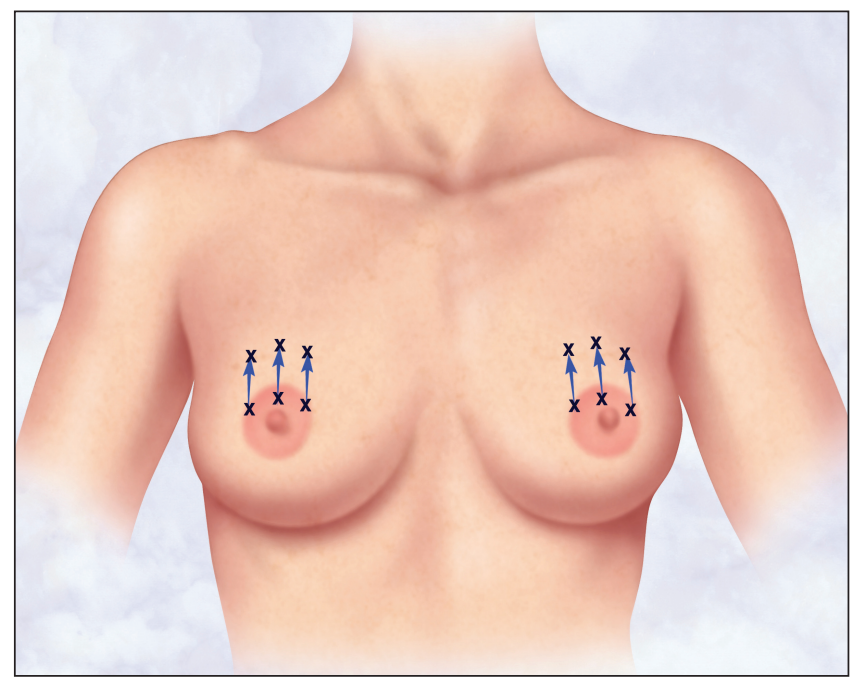

Figure 1) Anteroposterior view demonstrating the position of the internal mastopexy sutures in relation to the nipple-areola complex

pocket. The internal mastopexy sutures (2-0 vicryl) are placed in the superficial fascia of the breast. If available, an endoscopic needle driver greatly facilitates the suture placement (however, a long needle driver will suffice). The first bite is taken at the superior aspect of the nipple-areola complex and the second is taken cephalad to this (Figures 1 and 2). The distance between the bites depends on the amount of correction desired in nippleareola position. The bites will need to be approximately $2.5 \mathrm{~cm}$ apart for each centimetre of nipple-areolar elevation, taking care not to dimple the skin. The sutures effectively plicate the superficial fascia from the deep surface. Two to three sutures are placed depending on the base diameter of the breast. The implant is then inserted (and filled to the appropriate volume with saline). The incision is tailor-tacked, the patient is seated upright and the result assessed. If the result is acceptable, the patient is returned to the supine position and the incision is closed in a multilayer fashion. Otherwise, the implants are removed and alterations are made in the internal mastopexy sutures before reassessing in the upright position.

\section{RESULTS}

Figure 3 demonstrates a bilateral internal mastopexy combined with $460 \mathrm{~mL}$ subglandular silicone gel implants used to correct bilateral moderate grade II ptosis and hypomastia. The patient in Figure 4 has bilateral hypomastia, mild grade II ptosis on the left and moderate grade II ptosis on the right. In addition to $400 \mathrm{~mL}$ subglandular silicone gel implants, this patient had differential internal mastopexy sutures with the right side being corrected more than the left. While the correction seen at the six-month follow-up is not perfect, it represents a significant improvement over the preoperative asymmetry and, other than periareolar incisions, there is no other technique available to achieve this amount of correction.

\section{DISCUSSION}

Women presenting for mastopexy desire restoration of a full, youthful breast. However, the extent of the scarring is often a major concern. Periareolar and vertical techniques leave scars on the breast mound and, on occasion, these scars can be

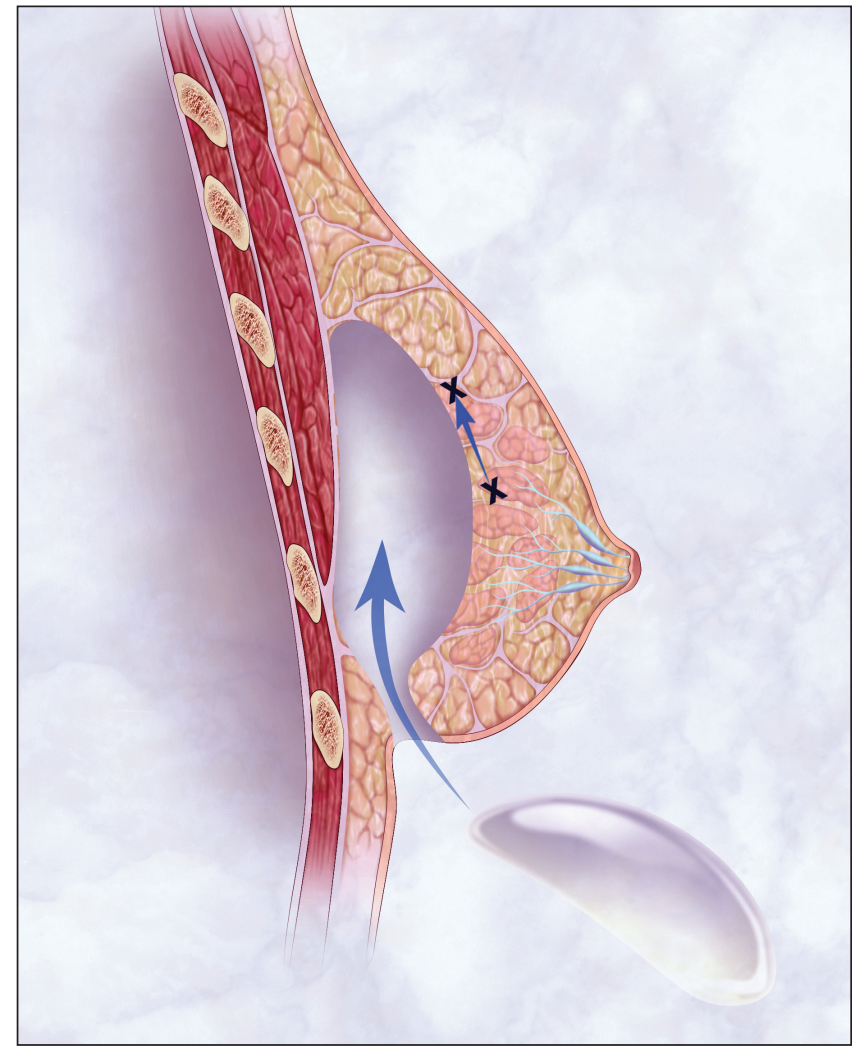

Figure 2) Lateral cross section demonstrating the placement of the internal mastopexy sutures

somewhat visible. This internal mastopexy was designed to be an alternative to the external procedures. It is applicable to patients in which the nipple is to be repositioned up to $3 \mathrm{~cm}$ more cephalad. There are two distinct advantages to this technique. First and foremost, it does not leave a mastopexy scar on the breast. Second, in patients with breast thickness less than $4 \mathrm{~cm}$, it may prove to be safer than other techniques that would damage both the superficial and deep surface. It is a simple, safe, reproducible procedure that adds approximately $10 \mathrm{~min}$ to the operating time (the same or less than most other mastopexy techniques).

The senior author has performed this procedure on over 120 patients, with a mean follow-up of two years. Patients and the surgeon have expressed satisfaction with the procedure. Ptosis and nipple-areola complex position (up to $3 \mathrm{~cm}$ ) have been reliably and safely corrected. The longest follow-up at this point is over five years and the result has proven to be stable. There have been no complications from the additional sutures. Specifically, there has been no apparent increased rate of capsular contracture and there have been no infections, implant ruptures, hematomas, seromas or skin loss (even with combined augmentation mastopexy with $800 \mathrm{~mL}$ silicone gel implants). When repositioning the nipple-areola complex greater than $2 \mathrm{~cm}$, there can initially be minor redundancy of the skin. Resolution of the redundancy corrects in two to three months and has not resulted in recurrent ptosis. Presumably, the internal mastopexy sutures hold the nippleareola complex in the appropriate position while the superficial fascia heals.

The internal mastopexy technique is most successful in patients with grades I or II ptosis. Considering the spectrum of 


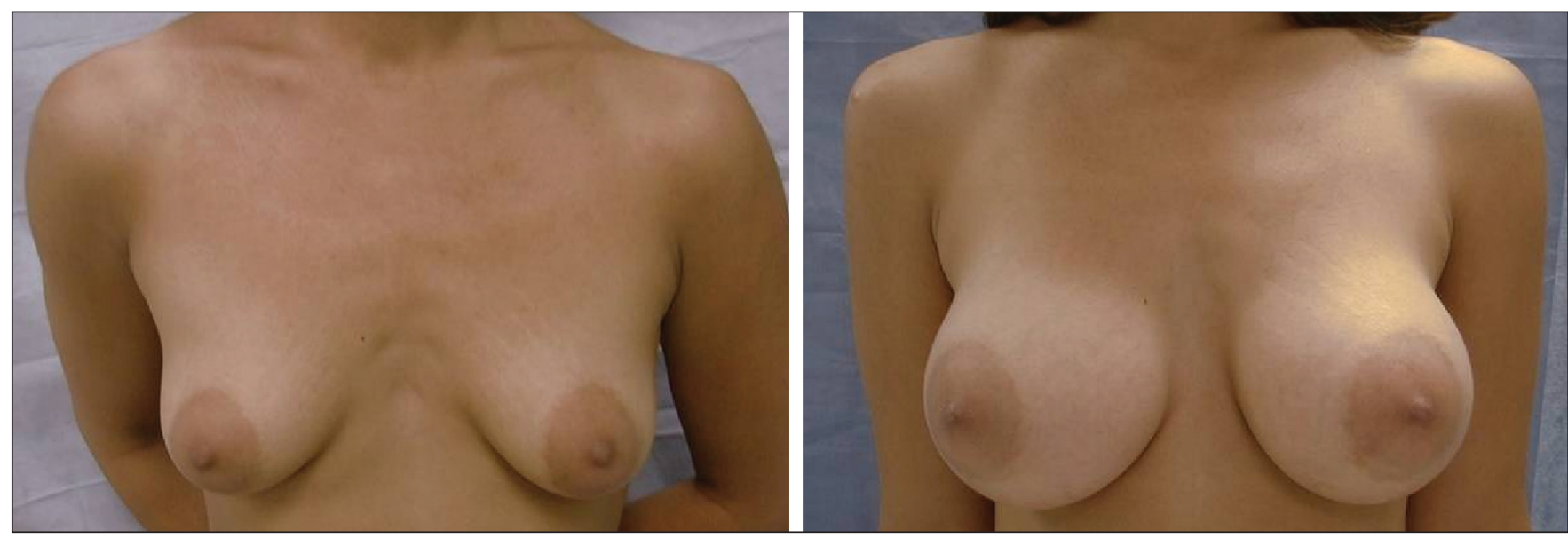

Figure 3) Preoperative and six-month follow-up photographs for a patient who underwent bilateral subglandular silicone gel breast augmentation with bilateral internal mastopexy
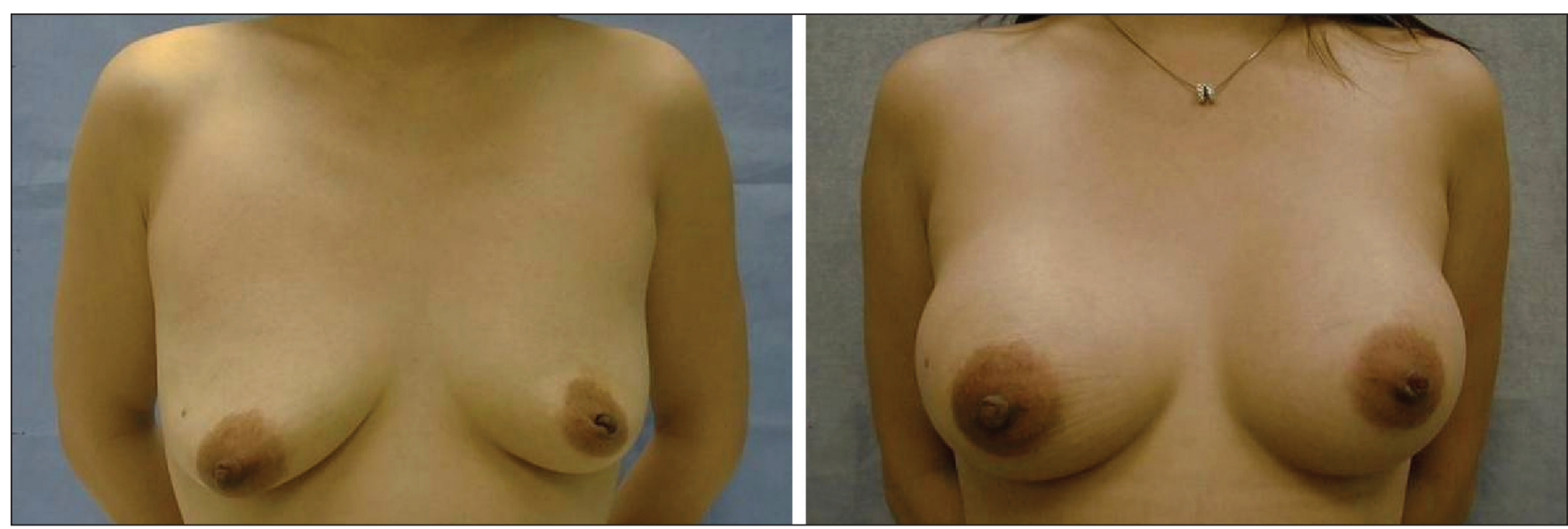

Figure 4) Preoperative and six-month follow-up photographs for a patient who underwent bilateral subglandular silicone gel breast augmentation with asymmetric bilateral internal mastopexy

shapes and volumes, this technique is not applicable to all patients. For example, in patients who require the nipple to be repositioned greater than $3 \mathrm{~cm}$, this technique is unlikely to be successful. Current discussion of this situation suggests that a staged approach with a Wise pattern mastopexy and augmentation would be prudent (6).

We hope that surgeons will find the internal suture mastopexy technique to be a valuable procedure in selected patients. Additional follow-up will establish the long-term durability of this procedure.

ETHICAL STATEMENT: Human subjects were involved in the research reported on in the present paper and informed consent was obtained by all subjects herein.

\section{REFERENCES}

1. Regnault B. Breast ptosis: Definition and treatment. Clin Plast Surg 1976;3:193-203.

2. Rohrich RJ, Thornton JF, Jakubietz RG, Jakubietz MG, Brunert JG. The limited scar mastopexy: Current concepts and approaches to correct breast ptosis. Plast Reconstr Surg 2004;114:1622-30.

3. Wise RJ. A preliminary report on a method of planning the mammaplasty. Plast Reconstr Surg 1956;17:367-75.

4. Mahabir RC, Peterson BD, Williamson JS, Valnicek SM, Williamson DG, East WE. Locally administered ketorolac and bupivacaine for control of postoperative pain in breast augmentation patients. Plast Reconstr Surg 2004;114:1910-6.

5. Whidden PG. The tailor-tack mastopexy. Plast Reconst Surg 1978;62:347-54.

6. Spear SL, Pelletiere CV, Menon N. One-stage augmentation combined with mastopexy: Aesthetic results and patient satisfaction. Aesth Plast Surg 2004;28:259-67. 